\title{
Performance analysis for the long-term field verifications of grid-connected photovoltaic system: case study in Taiwan
}

\author{
Jen-Cheng Wang ${ }^{\mathrm{a}}$, Hsuan-Hshiang Hsu ${ }^{\mathrm{a}}$, Min-Sheng Liao ${ }^{\mathrm{a}}$, \\ Kun-Chang Kuo ${ }^{\text {, }}$ Joe-Air Jiang ${ }^{\text {a,b,* }}$ \\ ${ }^{a}$ Department of Bio-Industrial Mechatronics Engineering, National Taiwan University, \\ No. 1, Sec. 4, Roosevelt Road, Taipei 10617, Taiwan \\ ${ }^{b}$ Education and Research Center for Bio-Industrial Automation, National Taiwan University, \\ No. 1, Sec. 4, Roosevelt Road, Taipei 10617, Taiwan
}

\begin{abstract}
In recently years, global warming and climate change have gradually emerged. Photovoltaic (PV) energy has attracted intensive research effort, due to its unique properties and versatile applications. The power generated by the PV systems can be directly supplied to buildings or electrical grids to reduce high costs associated with using energy such as electricity and fossil fuels. However, due to the low energy-conversion efficiency of the PV systems, it is necessary to improve the performance of the PV systems by tackling energy loss issues. In order to achieve the maximum power output in real time, the Maximum Power Point Tracking (MPPT) control technique is essential to PV-assisted generation systems. In this study, we have evaluated the performance of a PV system on the roof of the bulling at National Taiwan University. The tracking of the maximum power output of the PV system can be achieved in real time, while the power tracking with a Perturbation and Observation (P\&O) method remains unchanged. Based on experimental results obtained from an outdoor environment over one year, the performances of PV modules under outdoor operations are deeply affected by their location and environmental conditions. The relationship between the performances of the PV system and the irradiation conditions for the multi-crystalline silicon PV modules utilized in the proposed system was examined in detail.
\end{abstract}

Keywords: Energy conservation, Maximum Power Point Tracking (MPPT), Perturbation and Observation (P\&O) method, photovoltaic $(P V)$ system

\section{Introduction}

A critical issue regarding the negative effects brought by global warming and climate change has gradually emerged in recent years [1]-[6]. The photovoltaic (PV) energy, wind energy, and fuel cells have been used to reduce certain carbon dioxide $\left(\mathrm{CO}_{2}\right)$ emissions and efficiently mitigate the negative effect of global warming [1]-[6]. PV energy has attracted intensive research effort because of its unique properties and versatile applications. PV systems are utilized to directly convert light energy into electric power so that the use of fossil fuels can be decreased. They generate electricity from sunlight instead of using fossil fuels, so no gas is emitted. This merit makes PV systems a reliable energy source and an efficient mitigation lever against global warming [7], [8]. However, the energy-conversion efficiency of the PV system is still low. Hence, it is worthy to pay much attention to improve the performance of PV system and further investigate energy conversion processes and energy loss issues. The PV system exhibits a characteristic of extremely nonlinear current-voltage $(I-V)$ which varies with array temperature and solar irradiation at all times. However, they are deeply affected by environmental factors such as irradiation intensity, temperature, incident angle, non-uniform irradiation, and shading [9]-[12]. With the

\footnotetext{
* Manuscript received July 10, 2017; revised October 24, 2017.

Corresponding author. Tel.: +886-2-3366-5364; E-mail address :jclwang@ntu.edu.tw.

doi: $10.12720 /$ sgce.6.4.219-224
} 
changes of these factors, it will lead to the changes in I-V characteristics of fixed PV modules and the reduction of output power at the Maximum Power Point (MPP) [12]-[14].

Further, the characteristics and performance of a PV generation system are deeply affected by weather conditions when the PV generation system is located in an outdoor environment [13]-[16]. The output power of PV modules was inherently deteriorated because of the variation of temperature and irradiation intensity. From the experimental results and field-test data [13]-[16], it was observed that the changes in irradiation mainly affect the PV output current, while the ambient temperature changes mainly influence the PV output voltage, resulting in the variations of the maximum output power. The MPP and electrical parameters for the PV modules are also influenced by the thermal effect under solar irradiation. Therefore, it is difficult to ensure that PV modules maintain maximum power output under all possible system operation conditions. A Maximum Power Point Tracking (MPPT) control method is required for PV generation systems to achieve a maximum power output at real time. Some various methods, such as the lookup table method [17], [18], perturb-and-observe method [19]-[21], and incremental conductance method [22], have been proposed applying the MPPT algorithm to gain the maximum utilization efficiency of the PV system.

In this study, we have evaluated the performance of a PV system on the roof of the bulling at National Taiwan University. The output power and energy harvesting performance of the PV system have been estimated and the power tracking with a $\mathrm{P} \& \mathrm{O}$ method remains unchanged. The tracking of the maximum power output of the PV system can be achieved in real time. It is expected that using PV systems is beneficial to reduce certain $\mathrm{CO}_{2}$ emissions and cut back the use of fossil fuels. Based on experimental results obtained from an outdoor environment over one year, the performances of PV modules under outdoor operations are deeply affected by their location and environmental conditions. The dependence of irradiation condition on the performances of the PV system are examined and discussed in detail as well. All the detailed calculation results are also consistent with the observations.

\section{Experimental Procedure}

We installed a PV-assisted generation system on the south side of the bulling to maximizing the solar energy efficiency. A $3.89 \mathrm{~kW}$ photovoltaic system was placed on the roof of the bulling at the campus of National Taiwan University, $121.22^{\circ}$ east longitude and $25.01^{\circ}$ north latitude. We were used the eighteenpiece multi-crystalline silicon modules connected in series-parallel to establish a $3.89 \mathrm{~kW}$ PV-assisted generation system. The specification of the PV modules utilized in this study was listed in Table 1 . The open-circuit voltage $V_{o c}$ and the short-circuit current $I_{s c}$ of the multi-crystalline silicon PV module were $36.83 \mathrm{~V}$ and $7.86 \mathrm{~A}$ measured under STCs: an irradiation intensity of $1000 \mathrm{~W} / \mathrm{m}^{2}$; AM 1.5G; and a temperature of $25^{\circ} \mathrm{C}$. The conversion efficiency of polysilicon silicon PV module also measured as $13.3 \%$ under the STCs. On the other hand, the voltage $V_{m p}$ and current $I_{m p}$ of a single PV module at the MPP are 29.6 V and 7.29 A, respectively. The PV module provided a maximum output power $P_{m p}$ of 216 $\mathrm{W}$ at the MPP.

First, the PV modules under solar irradiation collected solar energy and delivered the direct current (dc) power to the PV inverter during the PV system operation. Then, the PV inverter transformed the dc power into the alternating current (ac) power and fed it into the grid. The specification of the PV inverter (SLK4000, Powercom Co. Ltd.) utilized in the PV-assisted generation system was listed in Table 2. It had a maximum input power and maximum input voltage of $4.7 \mathrm{~kW}$ and $500 \mathrm{Vdc}$, a nominal dc voltage of 360 $400 \mathrm{Vdc}$, the MPP voltage range of $200-400 \mathrm{Vdc}$, and a maximum input current of $20 \mathrm{Adc}$. For the output part of PV inverter, it had a maximum output power of $4.4 \mathrm{~kW}$, a nominal output power of $4.0 \mathrm{~kW}$, an operating output voltage range of $198-256 \mathrm{Vac}$, and a nominal output current of 17.4 Aac with an output current distortion less than 5\%. The power factor of PV inverter is greater than 0.99 , and the maximum conversion efficiency of PV inverter is greater than $96 \%$. The power could be directly harvested by the PV inverters utilized in the PV-assisted generation system. The long-term experiments were conducted a field test to examine the performance of the $3.89 \mathrm{~kW}$ PV system from January 1, to December 31, 2012. Further, we were used the experimental data of the whole year of 2012 to evaluate 
the performances of the PV system and examine the relationship between the generation power of the PV system and the irradiation conditions.

Table 1. The specifications of the PV modules utilized in the PV system

\begin{tabular}{ll}
\hline Items & Specifications or description* \\
\hline Open-circuit voltage $V_{o c}$ & $36.83 \mathrm{~V}$ \\
Short-circuit current $I_{s c}$ & $7.86 \mathrm{~A}$ \\
Conversion efficiency & $13.3 \%$ \\
Voltage $V_{m p}$ at MPP & $29.6 \mathrm{~V}$ \\
Current $I_{m p}$ at MPP & $7.29 \mathrm{~A}$ \\
Maximum output power $P_{m p}$ at MPP & $216 \mathrm{~W}$ \\
\hline$*$ All data was measured under standard test conditions (STC): an irradiation \\
intensity of $1000 \mathrm{~W} / \mathrm{m}^{2}$, AM $1.5 \mathrm{G}$, and an ambient temperature of $25^{\circ} \mathrm{C}$.
\end{tabular}

Table 2. The specifications of the PV inverter utilized in the PV system in this study

\begin{tabular}{ll}
\hline Items & Specifications or description \\
\hline Maximum input power & $4.7 \mathrm{~kW}$ \\
Maximum input voltage & $500 \mathrm{Vdc}$ \\
Nominal dc voltage & $360-400 \mathrm{Vdc}$ \\
Maximum power point (MPP) voltage range & $200-400 \mathrm{Vdc}$ \\
Maximum input current & $20 \mathrm{Adc}$ \\
Maximum output power & $4.4 \mathrm{~kW}$ \\
Nominal output power & $4.0 \mathrm{~kW}$ \\
Operating output voltage range & $198-256 \mathrm{Vac}$ \\
Nominal output current & $17.4 \mathrm{Aac}$ \\
Output current distortion & $<5 \%$ \\
Power factor & $>0.99$ \\
Maximum conversion efficiency & $>96 \%$ \\
\hline
\end{tabular}

\section{Results and Discussion}

Fig. 1 was shown the irradiation intensity for the PV modules utilized in the PV system at different months in the year of 2012. It was found that the period of the lower solar irradiation intensity is January and February, respectively. On the other hand, the solar irradiation intensity was gradually increased from July to October and further decreased from November to December. The maximum and minimum values of the average irradiation intensity are $276.5 \mathrm{~W} / \mathrm{m}^{2}$ at July and $110.5 \mathrm{~W} / \mathrm{m}^{2}$ at January. The variations of solar irradiation intensity are deeply affected the performances of PV modules under outdoor operations, resulted in the deterioration of the generation power and output energy.

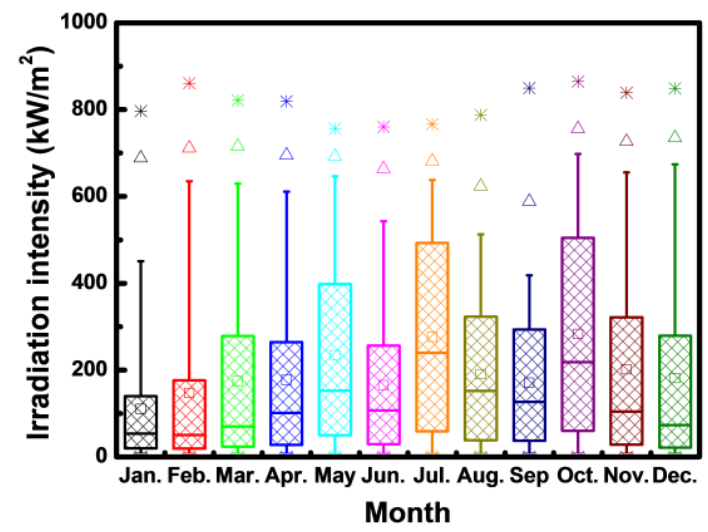

Fig. 1. Irradiation intensity for the PV modules utilized in the PV system at different months in the year of 2012.

The output power and energy harvesting performance of the PV system have been estimated and the power tracking with a $\mathrm{P} \& \mathrm{O}$ method remains unchanged. The generation power from the PV modules utilized in the PV system at different months in the year of 2012 was shown in Fig. 2. With the rise in the 
irradiation intensity, an increase in the output power is primarily caused by the rise to a linear increase in the photocurrent. It was found that the minimum and maximum values of the average generation power from the PV modules under solar irradiation are $0.44 \mathrm{~kW}$ at January and $1.07 \mathrm{~kW}$ at July. The generation power from the PV modules under outdoor operations was frequently varied with the change of the irradiation intensity. The period of the lower generation power from the PV modules is January and February; and the period of the higher generation power is from July to October, respectively. The higher generation power from the PV modules was due to the higher solar irradiation intensity. The tendency for the irradiation intensity was consistent with the variation of the values of generation power from the PV modules. This confirms that the relationship between the irradiation intensity and the generation power of the PV modules was highly and strongly depend on each other.

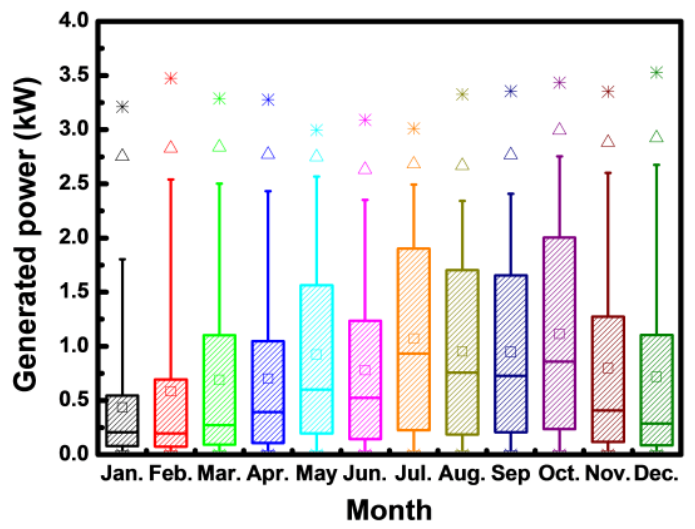

Fig. 2. The generation power from the PV modules utilized in the PV system at different months in the year of 2012.

We further analyzed the long-term field testing results to verify the performances of grid-connected PV system. Fig. 3 was shown the monthly output energy from the PV inverters with the P\&O method utilized in the PV-assisted generation system during the whole year of 2012. It was found that the monthly output energy of the PV inverter with the P\&O method from July to October was greater than that generated that of the PV inverter in the January and February. For example, the output energy of the PV inverter utilized in the PV-assisted generation system was 130 and $412 \mathrm{kWh}$ in January and July at the year of 2012, respectively. It was attributed to the higher solar irradiation intensity and the longer irradiation time. The experimental results demonstrated that the weather conditions are deeply affected the characteristics and performance of a PV generation system located in an outdoor environment.

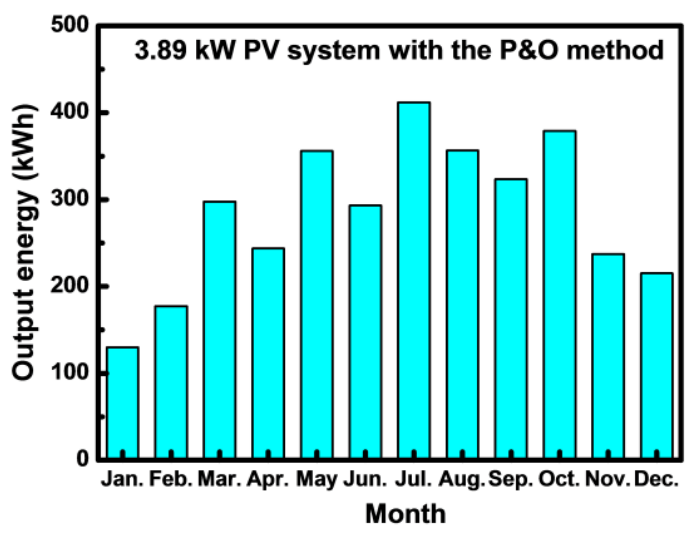

Fig. 3. The monthly output power of the PV inverter with the P\&O method utilized in the PV-assisted generation system in the year of 2012 .

The irradiation intensity and the generation performances of the $3.89 \mathrm{~kW}$ PV-assisted generation 
system in the year of 2012 were listed in Table 3. The values of the $95 \%$ percentage, average and $25 \%$ percentage of irradiation intensity were calculated and used to evaluate the weather conditions. The value of $95 \%$ percentage of irradiation intensity is between 600 and $700 \mathrm{~W} / \mathrm{m}^{2}$ during the whole year of 2012 . For the lower value of $95 \%$ percentage of irradiation intensity, it was attributed to the rain and typhoon. On the other hand, the period of the higher generation power and output power is from July to October. It was found that the irradiation intensity and average irradiation time from July to October was greater than the ones at other months. For example, the output power from PV modules and the average irradiation time was $130.0 \mathrm{kWh}$ and 1.08 (hour/day) in January and $412 \mathrm{kWh}$ and 3.42 (hour/day) in July at the year of 2012, respectively. Therefore, the generation performances of a PV generation system located in an outdoor environment were deeply affected by the solar irradiation and weather conditions.

Table 3. The monthly irradiation intensity and the generation performances of the $3.89 \mathrm{~kW} \mathrm{PV}$-assisted generation system in the year of 2012

\begin{tabular}{|c|c|c|c|c|c|c|c|c|}
\hline \multirow[t]{2}{*}{ Month } & \multicolumn{3}{|c|}{ Irradiation intensity $\left(\mathrm{W} / \mathrm{m}^{2}\right)$} & \multicolumn{3}{|c|}{ Generation power $(\mathrm{kW})$} & \multirow{2}{*}{$\begin{array}{l}\text { Output power } \\
\text { (kWh) }\end{array}$} & \multirow{2}{*}{$\begin{array}{l}\text { Average irradiation } \\
\text { time (hour/day) }\end{array}$} \\
\hline & At $95 \%$ & Average & At $25 \%$ & At $95 \%$ & Average & At $25 \%$ & & \\
\hline January & 450.7 & 110.5 & 19.4 & 1.80 & 0.44 & 0.08 & 130.0 & 1.08 \\
\hline February & 634.8 & 147.3 & 19.0 & 2.53 & 0.58 & 0.08 & 177.2 & 1.57 \\
\hline March & 629.3 & 174.9 & 23.9 & 2.50 & 0.69 & 0.09 & 297.7 & 2.47 \\
\hline April & 610.7 & 176.9 & 27.5 & 2.43 & 0.70 & 0.11 & 243.8 & 2.09 \\
\hline May & 646.3 & 234.3 & 50.0 & 2.57 & 0.92 & 0.20 & 356.2 & 2.96 \\
\hline June & 542.4 & 165.1 & 28.9 & 2.35 & 0.78 & 0.14 & 293.3 & 2.51 \\
\hline July & 637.9 & 276.5 & 58.8 & 2.49 & 1.07 & 0.22 & 412.0 & 3.42 \\
\hline August & 512.6 & 190.3 & 38.1 & 2.34 & 0.95 & 0.19 & 356.5 & 2.96 \\
\hline September & 418.2 & 170.7 & 37.3 & 2.41 & 0.95 & 0.21 & 323.4 & 2.77 \\
\hline October & 697.7 & 282.7 & 60.0 & 2.75 & 1.11 & 0.24 & 379.1 & 3.15 \\
\hline November & 655.3 & 201.4 & 28.3 & 2.60 & 0.80 & 0.12 & 237.5 & 2.04 \\
\hline December & 673.7 & 181.4 & 21.1 & 2.67 & 0.72 & 0.09 & 215.2 & 1.79 \\
\hline
\end{tabular}

\section{Conclusions}

The performances of grid-connected PV system on the roof of the bulling at National Taiwan University were verified using long-term field experiments. The experimental data for the whole year of 2012 were used to evaluate the relationship between the generation energy and the weather conditions. Based on the experimental results, it was found that the period of the lower irradiation intensity is January and February; and the period of the higher irradiation intensity is from July to October, respectively. On the other hand, the minimum and maximum values of the average generation power from the PV modules under solar irradiation are $0.44 \mathrm{~kW}$ at January and $1.07 \mathrm{~kW}$ at July. It was attributed to that the irradiation intensity in July was higher than the ones at other months.

Further, the variations of irradiation intensity and length of average irradiation time are also affected the output energy from PV modules under solar irradiation. The average irradiation time was 1.08 (hour/day) and 3.42 (hour/day) in in January and July at the year of 2012, respectively. Moreover, the output energy of the PV inverter utilized in the PV-assisted generation system was 130 and $412 \mathrm{kWh}$ in January and July at the year of 2012, respectively. It was attributed to the higher solar irradiation intensity and the longer irradiation time. Through the long-term field verifications, the generation performances of a PV generation system under outdoor operation were deeply affected by the solar irradiation and weather conditions. All the detailed calculation results are also consistent with the observations.

\section{Acknowledgement}

This work was financially supported in part by the Pan-Co International Company of Limited, the Yaude Information Ltd., and the Ministry of Science and Technology, Executive Yuan, Taiwan, under the grant numbers: MOST 103-2622-E-002-023-CC2, MOST 104-2622-E-002-010-CC2, and MOST 1052622-E-002-004-CC2. The authors would like to thank the research team members of Bioelectromagnetics Lab., BIME, NTU for their valuable suggestions and contributions to this work. 


\section{References}

[1] Gustavsson L, Börjesson P, Johansson B, Svenningsson P. Reducing $\mathrm{CO}_{2}$ emissions by substituting biomass for fossil fuels. Energy, 1995; 20(11):1097-1113.

[2] Dincer I, Rosen MA. A worldwide perspective on energy, environment and sustainable development. International Journal of Energy Research, 1998; 22(15):1305-1321.

[3] Dincer I. Environmental impacts of energy. Energy Policy, 1999; 27(14):845-854.

[4] Pelet X, Favrat D, Leyland G. Multiobjective optimisation of integrated energy systems for remote communities considering economics and $\mathrm{CO}_{2}$ emissions. International Journal of Thermal Sciences, 2005; 44(12):1180-1189.

[5] Quadrelli R, Peterson S. The energy-climate challenge: recent trends in $\mathrm{CO}_{2}$ emissions from fuel combustion. Energy Policy, 2007; 35(11):5938-5952.

[6] Münster M, Lund H. Use of waste for heat, electricity, and transport—challenges when performing energy system analysis. Energy, 2009; 34(5):636-644.

[7] Katti PK, Khedkar MK. Alternative energy facilities based on site matching and generation unit sizing for remote area power supply. Renewable Energy, 2007; 32(8):1346-1362.

[8] Nema P, Nema RK, Rangnekar S. Minimization of green house gases emission by using hybrid energy system for telephony base station site application. Renewable \& Sustainable Energy Reviews, 2010; 14(6):1635-1639.

[9] Zbeeb A, Devabhaktuni V, Sebak A. Improved photovoltaic MPPT algorithm adapted for unstable atmospheric conditions and partial shading. In: Proc. of International Conference on Clean Electrical Power, 2009:320-323.

[10] Tajuddin MFN, Arif MS, Ayob SM, Salam Z. Perturbative methods for maximum power point tracking (MPPT) of photovoltaic (PV) systems: a review. International Journal of Energy Research, 2015; 39(9):1153-1178.

[11] Jiang JA, Wang JC, Kuo KC, Su YL, Shieh JC. On evaluating the effects of the incident angle on the energy harvesting performance and MPP estimation of PV modules. International Journal of Energy Research, 2014; 38(10):1304-1317.

[12] Mutoh N, Ohno M, Inoue T. A method for MPPT control while searching for parameters corresponding to weather conditions for PV generation systems. IEEE Transactions on Industrial Electronics, 2006; 53(4):1055-1065.

[13] Kwon JM, Nam KH, Kwon BH. Photovoltaic power conditioning system with line connection. IEEE Transactions on Industrial Electronics, 2006; 53(4):1048-1054.

[14] Wang JC, Su YL, Shieh JC, Jiang JA. High-accuracy maximum power point for photovoltaic arrays. Solar Energy Materials and Solar Cells, 2011; 95(3):843-851.

[15] Hussein KH, Muta I, Hoshino T, Osakada M. Maximum photovoltaic power tracking: an algorithm for rapidly changing atmosphere conditions. IEE Proceedings - Generation, Transmission and Distribution, 1995; 142(1):59-64.

[16] Sera D, Kerekes T, Teodorescu R, Blaabjerg F. Improved MPPT method for rapidly changing environmental conditions. In: Proc. of IEEE International Symposium on Industrial Electronics, 2006:1420-1425.

[17] Hiyama T, Kouzuma S, Imakubo T. Identification of optimal operating point of PV modules using neural network for real time maximum power tracking control. IEEE Transactions on Energy Conversion, 1995; 10(2):360-367.

[18] Hiyama T, Kitabayashi K. Neural network based estimation of maximum power generation from PV module using environmental information. IEEE Transactions on Energy Conversion, 1997; 12(3):241-247.

[19] Sullivan CR, Powers MJ. A high-efficiency maximum power point tracker for photovoltaic arrays in a solar-powered race vehicle. In: Proc. of IEEE Power Electronics Specialists Conference, 1993:574-580.

[20] Gow JA, Manning CD. Controller arrangement for boost converter systems sourced from solar photovoltaic arrays or other maximum power sources. IEE Proceedings - Electric Power Applications, 2000; 147(1):15-20.

[21] Enslin JHR, Wolf MS, Snyman DB, Sweigers W. Integrated photovoltaic maximum power point tracking converter. IEEE Transactions on Industrial Electronics, 1997; 44(6):769-773.

[22] Wasynzczuk O. Dynamic behavior of a class of photovoltaic power systems. IEEE Transactions on Power Apparatus and Systems, 1983; PAS-102(1):3031-3037. 